\title{
Grain growth of Pennisetum glaucum (L.) R.Br. under well-watered and drought-stressed conditions
}

\author{
P. Bieler ${ }^{a}$, L.K. Fussell ${ }^{a}$ and F.R. Bidinger ${ }^{b}$ \\ "Pearl Millet Improvement Program, ICRIS.4T Sahelian Center, B.P. 12404, Niamey, Niger \\ 'Pearl Millet Improventent Program, ICRIS.4T, Patancheru, Andhra Pradesh 502334, India
}

(Accepted 24 June 1991)

\section{ABSTRACT}

Bieler, P., Fussell, L.K. and Bidinger, F.R., 1993. Grain growth of Pennisetum glancum (L.) R.Br. under well-watered and drought-stressed conditions. Field Crops Res., 31: 41-54.

The objective of this study was to investigate the possibility of relationships between grain growth parameters and drought response. Grain growth parameters of more than 70 millet lines were assessed under well-watered and postflowering drought-stress conditions in two field trials at the ICRISAT Sahelian Center, Sadoré, Niger. All the grain growth parameters based on thermal time varied more than two-fold between lines in both moisture environments. Single grain mass of the lines ranged from 4.3-10.9 mg under well-watered conditions and 3.4-9.4 mg under drought stress. When averaged across trials, $51 \%$ of the accounted variance of final grain mass could be explained by differences in the grain growth rate under well-watered conditions, while differences in the duration of the linear grain growth phase accounted for $37 \%$ of the variation in final grain mass.

Drought stress reduced the linear grain growth phase and, as a consequence, reduced final grain mass by up to $25 \%$. Lines with long grain filling periods under well-watered conditions had larger reductions in the grain filling period and in final grain mass under stress. In general, there was little effect of drought stress on the grain growth rate. However, because of the negative correlation of grain growth rate and linear grain growth phase, lines with higher grain growth rates in well-watered conditions had smaller reductions in grain filling period under stress. Grain growth rate accounted with $38 \%$ for the major part of the variation in grain mass under stress conditions.

Grain growth parameters in well-watered and drought-stress conditions were unrelated to drought tolerance as expressed by a drought response index, and were indicators of neither susceptibility nor tolerance to siress. However final grain mass was highly correlated to yield under stress. A feasible risk-reducing strategy in the likelihood of postllowering stress is to select pearl millet lines for drought escape with a high grain growth rate combined with a relatively short grain filling period.

\section{INTRODUCTION}

Pearl millet (Pennisetum glaucum (L.) R.Br.) is the predominant cereal of the drought-prone Sahelian zone of West Africa. Annual rainfall in this zone $(300-600 \mathrm{~mm})$ is characteristically variable and undependable (Sivakumar, 
1986), and has been persistently below average across the zone since the late 1960's (Forest, 1982; Sivakumar, 1987). More importantly, rainfall during the month of August when the soil profile normally fills, storing water for the grain filling period of the crop during September/October, has declined by as much as $40 \%$ in some locations (Sivakumar, 1989). As a consequence, pearl millet grown in the Sahelian zone is frequently subjected to drought during grain filling.

Pearl millet is severely affected by drought occurring during the grain filling stage which can reduce grain yields by up to $50 \%$ (Mahalakshmi and Bidinger, 1985; Fussell et al., 1991). Fussell et al. (1991) found that reduced grain yields from postflowering drought stress were primarily due to reduced grain numbers per panicle and grain mass. Reduction in grain mass, caused by drought stress during the grain filling period (GFP), can be due either to a reduction in grain growth rate (GGR) and/or length of GFP. The process of grain growth and the role of these grain growth parameters in drought response of pearl millet have not been elucidated in the literature.

There exists genetic variation in pearl millet for single grain mass (Burton and Powell, 1968), which varies from 3.5 to $16.0 \mathrm{mg}_{\text {grain }}{ }^{-1}$ (Rachie and Majmudar, 1980). Fussell and Pearson (1978) described the grain filling period in pearl millet in terms of two phases: an initial short lag phase (LP) when little dry weight accumulation takes place and presumably cell differentiation occurs, and a subsequent linear grain growth phase (LGGP). These authors found that differences in both the length of the grain filling period and the grain growth rate in the LGGP were correlated with grain mass differences between pearl millet lines. However, the GGR accounted for most of the variation ( $91 \%$ vs. $8 \%$ ). Phenotypic differences for these parameters were found to be more genetic than environmental in rice (Oryza sativa L.) (Jones et al., 1979) and wheat (Triticum aestivtum L.) (Bruckner and Frohberg, 1987), suggesting that these parameters could be used in a selection program, if this was warranted. For wheat, Bruckner and Frohberg (1987) proposed that a high GGR with a relatively short duration was a desirable, risk-reducing strategy for postflowering stress.

The objectives of this study were: (1) to examine the extent of genotypic differences in grain growth of pearl millet in well-watered and postflowering drought-stressed conditions; (2) to ascertain the relationships of grain growth parameters to yield and yield components under well-watered and stressed conditions, in order to understand their importance in yield determination; and (3) to investigate possible relations to drought tolerance.

\section{MATERIALS AND METHODS}

\section{Experimental design and crop management}

Two postflowering drought-screening field trials were conducted at the ICRISAT Sahelian Center, Sadoré $\left(13^{\circ} \mathrm{N}, 2^{\circ} \mathrm{E}\right)$ in Niger during the hot dry- 
season (February-May) in 1988 and 1989. The experimental design was a modified split-plot, with main plots (irrigation treatments) replicated three times and sub-plots (millet lines) repeated twice within each main plot. Irrigation treatments, through overhead sprinklers, consisted of a well-watered control and a postflowering stress. Both irrigation treatments received regular irrigation on a 4- to 7-day cycle ( $38 \mathrm{~mm}$ per irrigation). For the stress treatment, irrigation was discontinued when $50 \%$ of the lines reached $50 \%$ flowering, simulating an early ending of the rains.

Plots consisted of four rows, $0.75 \mathrm{~m}$ apart, of 14 (in 1988) and 12 (in 1989) hills spaced at $40 \mathrm{~cm}$. Discarding the first hill as border, only the first five hills in the two middle rows were used for grain growth sampling. The rest of the plot was used to determine the yield parameters. Further details of these trials and conditions under which they were conducted are fully described in the previous paper (Fussell et al., 1991).

Forty-five millet lines were included in both field trials but 42 and 41 lines were included in the analysis in 1988 and 1989, respectively. The genetic material grown in these trials was advanced breeding lines, released varieties and local land races from West Africa, representing a diversity of morphological characteristics. Entry composition of the two trials varied between years.

\section{Observations}

Date of flowering for individual plots was determined when $50 \%$ of the stigmas had emerged on 50\% of all the inflorescences in the plot (Maiti and Bidinger, 1981). Individual inflorescences of both main stems and tillers were tagged on their date of flowering. The inflorescences were divided into two groups for monitoring of grain growth on the basis of mean time of flowering of a plot. The first group (EF) consisted of inflorescences flowering before the mean flowering time of the plot and the second group (LF) of inflorescences flowering after this time. This separation was undertaken to observe any differences of grain growth characters for early and late inflorescences within a line under both well-watered and drought-stress environments.

Samplings were staggered across the replications such that one sample was taken per line and treatment from either of replications 1 to 3 or 4 to 6 for each day resulting in a set of data with two replications. For EF and LF, samples of at least 100 grains were taken midway along the inflorescences daily from day 5 to day 19 after the flowers were tagged in the well-watered control and from day 5 to day 16 in the stress treatment in 1988. In 1989, daily sampling was reduced (day 6 to day 17 in the well-watered control and day 6 to day 14 in the stress treatment). These sampling periods approximate the LGGP in each treatment. Further, a total of 18 samples per line and replication group (six panicles per replication ) were taken randomly at 25 days after flowering (i.e. maturity; Maiti and Bidinger, 1981) in each treatment to determine final grain mass after the end of grain filling. Inflorescences were 
sampled once only. Grain samples were oven-dried for $24 \mathrm{~h}$ at $70^{\circ} \mathrm{C}$, handthreshed, counted and their 100-grain mass determined.

\section{Data analysis}

The grain growth and development were based on thermal time. The use of thermal time was necessary for line comparisons, as duration of pearl millet grain development is determined primarily by temperature (Fussell et al., 1980; Ong, 1983) and there were variations in temperature between and within the seasons. For temperatures below the optimum for grain growth, thermal time $\left(\Theta_{2}\right)$ was calculated as:

$\Theta_{1}=\sum_{i=1}^{n}\left(T_{i}-T_{\mathrm{b}}\right)$

where $T_{i}$ is mean temperature for the $i$ th day and $T_{\mathrm{b}}$ is the base temperature below which grain growth is zero. For supra-optimal temperatures. thermal time $\left(\Theta_{2}\right)$ was calculated as:

$\Theta_{2}=\sum_{i=1}^{n}\left(T_{\mathrm{m}}-T_{i}\right)$

where $T_{\mathrm{m}}$ is the maximum temperature above which grain growth ceases. By expressing equation (2) as:

$\Theta_{1}=\sum_{i=1}^{n}\left(T_{\mathrm{m}}-T_{i}\right) \Theta_{1} / \Theta_{2}$

where $\Theta_{1} / \Theta_{2}=\left(T_{\mathrm{o}}-T_{\mathrm{b}}\right) /\left(T_{\mathrm{m}}-T_{\mathrm{o}}\right)$ and $T_{\mathrm{o}}$ is the optimum temperature for grain growth, thermal time can be accumulated as ${ }^{\circ} \mathrm{Cday}$ using equations (1) and (3). Thermal time was calculated using a $T_{\mathrm{b}}$ of $10^{\circ} \mathrm{C}\left(\mathrm{Ong}, 1983\right.$ ), a $T_{\mathrm{o}}$ of $33^{\circ} \mathrm{C}$ (Fussell et al, 1980; Ong, 1983) and a $T_{\mathrm{m}}$ of $45^{\circ} \mathrm{C}$. Both $T_{\mathrm{o}}$ and $T_{\mathrm{m}}$ have not been accurately determined for grain development in pearl millet. The cardinal temperatures used are supported by the findings for other development processes of the crop (Garcia-Huidobro et al, 1982; Ong and Monteith, 1985) and the observation that $T_{\mathrm{b}}$ is nearly constant for a range of developmental processes in at least one line of pearl millet (Ong and Monteith, 1985) and was assumed to be the same for grain filling. Air temperatures were recorded at the meteorological station at Sadoré.

Linear regressions were fitted to the grain sample data taken during the LGGP to determine the GGR and the length of LP (after the method of Johnson and Tanner, 1972). The GGR was expressed as milligrams per grain per ${ }^{\circ}$ Cday. Lag phase was derived by setting the regression of the LGGP to a grain mass of zero, and expressed as ${ }^{\circ} \mathrm{Cday}$ from flowering. Duration of GFP 
was calculated by setting the regression to the final grain mass determined from the maturity sample. Linear grain growth phase (LGGP) was derived as the period from the end of LP to end of GFP (i.e. GFP-LP). For both irrigation treatments, the samples for EF and LF were initially kept separate and their grain growth characteristics analyzed. Finally, the two samples were combined to calculate mean line grain growth attributes in both environments.

Relationships between grain growth characteristics and yield attributes were determined using correlation analysis. In addition, their correlation to drought tolerance (the drought response index [DRI]) and time to flowering were calculated for the sub-sets of 34 lines analyzed in both years. The DRI is based on the assumption that grain yield under stress is a function of potential yield, time to flowering and a drought response, and is further explained in Fussell et al. (1991).

\section{RESULTS}

\section{Grain growth under well-watered conditions}

There was considerable genotypic variability for the components of the duration of grain filling (LP, LGGP, GFP), the GGR and the final grain mass under well-watered conditions, in both years (Table 1). The length of GFP and LGGP, and the GGR varied nearly two-fold between lines in both years, while the length of LP varied up to three-fold. The overall range of 265$495^{\circ} \mathrm{Cday}$ for GFP represents 13 to 22 days (at mean temperature of 30 $32^{\circ} \mathrm{C}$ ) and is consistent with previous studies (Fussell and Pearson, 1978; Fussell et al., 1980; Ong, 1983; Bishnoi et al., 1985). There was no significant difference between the lines means for LGGP, GGR and final grain mass between the two years. For the mean final grain mass of all lines, there was significant variation in 1988 only. In 1989, mean LP and GFP were slightly longer than observed in 1988.

The timing of flowering of a single inflorescence in relation to the distribution of flowering within a line had a significant influence on grain growth parameters under well-watered conditions only in 1989 (Table 2). Grains of EF had, on average, longer LP (significant at $P<0.01$ only in 1989). The average LGGP for the EF was the same as the LF. As a result, the mean GFP for all lines was slightly longer for the LF in 1988, but significantly shorter in 1989. The GGR, meaned across all lines, was not significantly affected by sampling inflorescences from the first or second half of the flowering distribution. Under well-watered conditions only four out of 42 lines in 1988 and three out of 41 lines in 1989 had a significantly lower GGR for LF. However, the final grain mass was significantly reduced in the LF in both years.

The relationships of grain growth parameters to each other and to certain yield attributes under well-watered conditions were examined using simple 


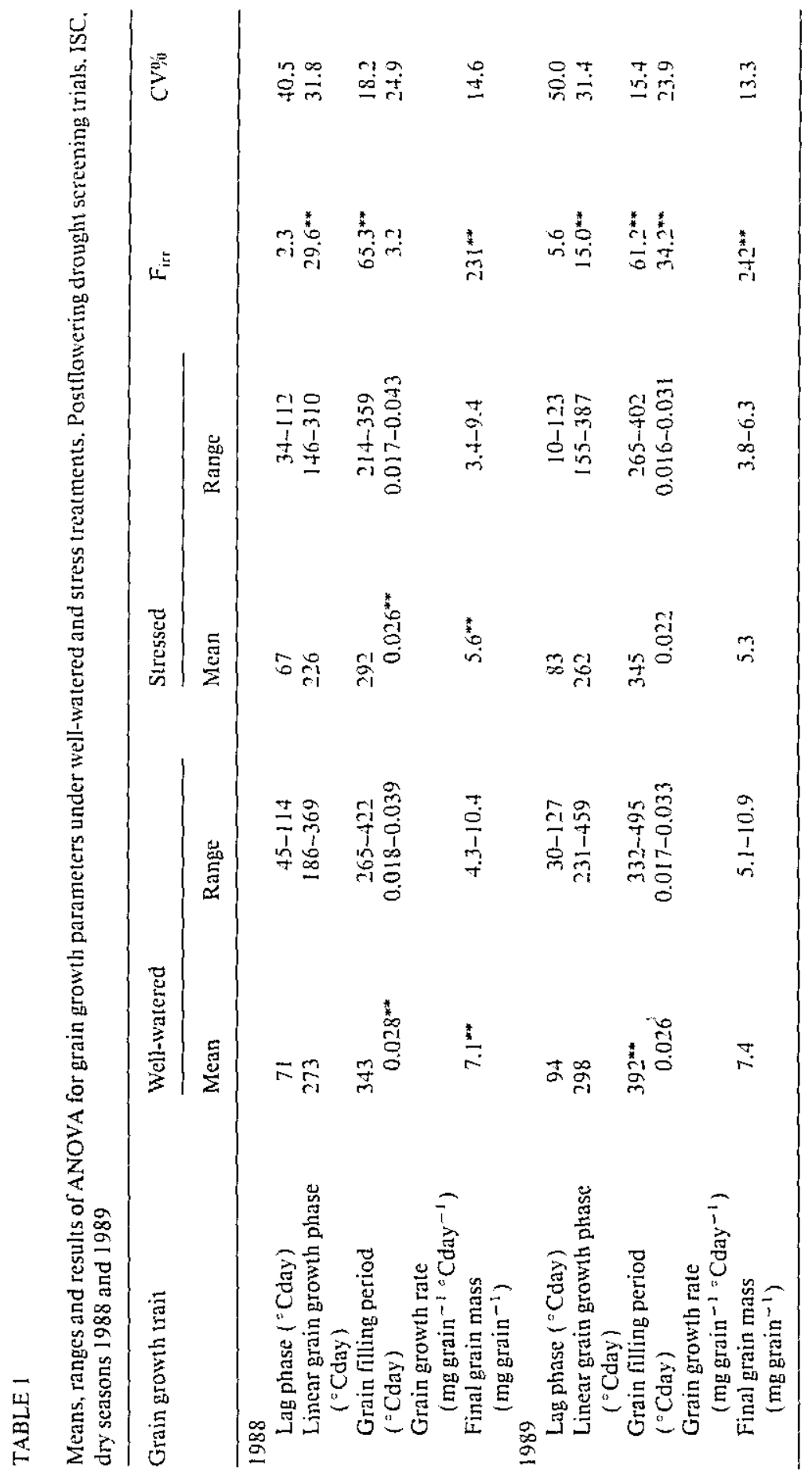


TABLE 2

Means of grain growth parameters from inflorescences of the first and second half of the flowering distribution in well-watered and stress treatments. Postllowering drought screening trials. ISC, dry seasons 1988 and 1989

\begin{tabular}{|c|c|c|c|c|c|c|}
\hline \multirow[t]{2}{*}{ Grain growth trait } & \multicolumn{3}{|c|}{ Well-watered } & \multicolumn{3}{|l|}{ Stressed } \\
\hline & EFa mean & $\mathrm{LF}^{\mathrm{a}}$ mean & $\mathrm{F}_{5}{ }^{\mathrm{a}}$ & EF mean & LF mean & $\mathrm{F}_{\mathrm{s}}$ \\
\hline \multicolumn{7}{|l|}{1988} \\
\hline Lag phase ( ${ }^{\circ}$ day) & 74 & 68 & 1.79 & 73 & 60 & $10.9^{* *}$ \\
\hline $\begin{array}{l}\text { Linear grain growth phase } \\
\left({ }^{\circ} \mathrm{Cday}\right)\end{array}$ & 267 & 277 & 0.60 & 230 & 221 & 0.69 \\
\hline Grain filling period & 341 & 345 & 0.14 & 303 & 281 & $9.2^{* * *}$ \\
\hline$\left({ }^{\prime}\right.$ Cday $)$ & 0.028 & 0.027 & 1.77 & 0.028 & 0.025 & 5.65 \\
\hline $\begin{array}{l}\text { Grain growth rate } \\
\left(\mathrm{mg} \text { grain }{ }^{-1}{ }^{-} \mathrm{Cday}^{-1}\right)\end{array}$ & & & & & & \\
\hline $\begin{array}{l}\text { Final grain mass } \\
\left(\mathrm{mg} \mathrm{grain}^{-1}\right)\end{array}$ & 7.16 & 7.06 & $9.1^{*}$ & 6.05 & 5.09 & $60.6^{* *}$ \\
\hline \multicolumn{7}{|l|}{1989} \\
\hline Lag phase ( ${ }^{\circ}$ Cday) & 110 & 78 & $52.7^{* * *}$ & 101 & 64 & $19.8^{* *}$ \\
\hline $\begin{array}{l}\text { Linear grain growth phase } \\
\left({ }^{\circ} \mathrm{Cday}\right)\end{array}$ & 302 & 294 & $0.0 ́ 3$ & 273 & 252 & 1.74 \\
\hline Grain filling period & 411 & 372 & $31.1^{* *}$ & 373 & 316 & $39.9^{* *}$ \\
\hline $\begin{array}{l}\left({ }^{\circ} \mathrm{Cday}\right) \\
\text { Grain growth rate } \\
\quad\left(\mathrm{mg} \text { grain }^{-1}{ }^{\circ} \mathrm{Cday}^{-1}\right)\end{array}$ & 0.027 & 0.025 & 8.01 & 0.024 & 0.021 & 7.64 \\
\hline $\begin{array}{l}\text { Final grain mass } \\
\left(\text { mg grain }^{-1}\right)\end{array}$ & 7.82 & 6.96 & $54.7^{* *}$ & 6.06 & 4.58 & $113^{* *}$ \\
\hline
\end{tabular}

${ }^{a} \mathrm{EF}=$ first half of the flowering distribution, $\mathrm{LF}=$ second half of the flowering distribution, $\mathrm{F}_{\mathrm{s}}=$ variance between samples.

$* P<0.05 ; * * P<0.01$.

correlation analysis (Table 3 ). The length of LGGP and GFP as well as the GGR were positively correlated with final grain mass; lines with a higher grain mass had longer LGGP and faster GGR. Long LGGP were associated with short LP and low GGR (the latter only in 1989). Yield attributes, such as grain yield per panicle, threshing percentage and grain yield itself were unrelated or inconsistently related across years to the grain growth parameters.

Genotypic differences in final grain mass in well-watered conditions were those associated with differences in GGR in the linear phase of grain growth and length of LGGP. This was shown with multiple linear regression analysis. When averaged across the two years, $51 \%$ of the accounted variance of final grain mass could be explained by differences in the GGR in the linear phase, $37 \%$ by differences in LGGP, with only $9 \%$ attributed to LP differences.

\section{Grain growth under postflowering drought stress}

The extent of genotypic variation for grain growth parameters observed under well-watered conditions was maintained under postflowering drought 


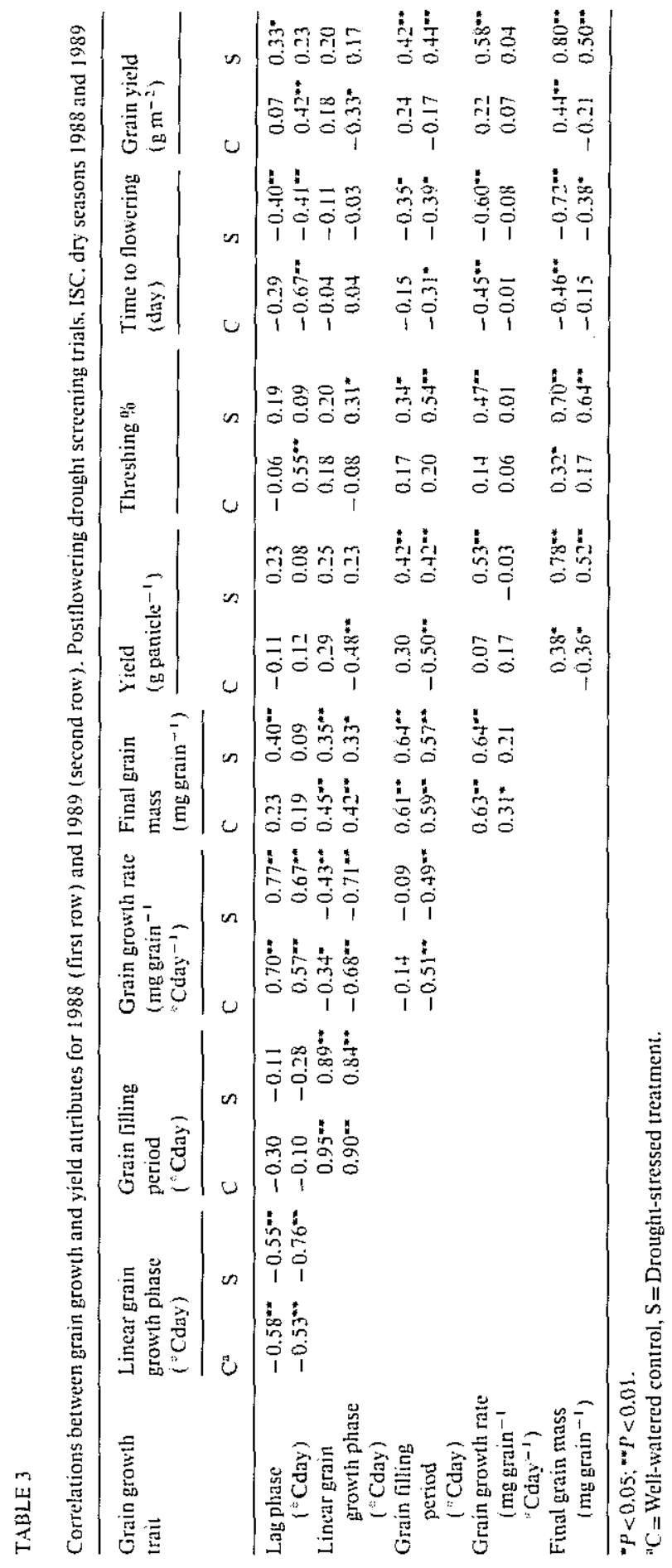


stress which reduced average final grain mass by $21 \%$ in 1988 and $28 \%$ in 1989 (Table 1).

Total GFP and LGGP were significantly reduced by postflowering drought stress, when compared with well-watered conditions (Table 1 ). In both years average GFP was shortened by between 47 and $51^{\circ} \mathrm{Cday}$ (i.e. more than 2 days) due to the imposed stress. Mean GGR (all lines) was not affected by drought stress in 1988 (compared to the well-watered control, Table 1). However, in 1989 drought stress significantly $(P<0.01)$ reduced the mean GGR by $15 \%$ (Table 1). Nonetheless, only three of the 41 lines showed a significantly $(P<0.05)$ lower GGR under drought stress in 1989. and there was only one such line in 1988. In 1988 high GGR were positively $(P<0.05)$ associated with the early flowering lines, which also had heavier grains. These trends, evident though not always significant under well-watered conditions, were enhanced under postflowering drought stress.

Comparison of grain growth parameters from EF and LF samples shows a reduction of all in the LF compared with the EF under postflowering stress (Table 2), as expected. Final grain masses were reduced in the later inflorescences because of shorter LP and LGGP. However, the mean GGR (all lines) was not significantly different between EF and LF with only five out of 42 lines in 1988, and eight out of 41 lines in 1989 having a lower GGR for inflorescences from the second half of the flowering distribution.

Although postflowering drought stress conspicuously reduced GFP, multiple linear regression analysis indicated that variation in GGR still accounted for the greater proportion of final grain mass difference among lines. When meaned across years, GGR, LGGP and LP accounted for 38\%, 34\% and $6 \%$ of the variability of the final grain mass under stress, this being very similar to that of the well-watered treatment.

Several of the interrelationships between grain growth parameters and final grain mass found under well-watered conditions were maintained under postflowering stress conditions (Table 3 ). Simple correlation analysis confirmed the overall importance of LGGP and GFP in determining final grain mass. The variation in genotypic response to stress was related to the time of flowering of a line through the negative association of time of flowering with LP (Table 3$)$. As one might expect final grain mass was significantly $(P<0.01)$ correlated with threshing percentage, grain yield per panicle and grain yield under postflowering drought stress. Grain filling period was highly correlated to grain yield per panicle in the stress. However, the relationships of both grain mass and GFP to yield attributes was largely an expression of drought escape, as the correlations were much reduced when the data were analyzed using partial correlation analysis, holding flowering date constant. Other grain growth parameters were mostly unrelated or inconsistently related to these yield attributes. 
TABLE 4

Correlation of drought response index (DRI) to grain growth parameters and yield attributes. Postflowering drought screening trials, ISC, dry seasons 1988 and 1989

\begin{tabular}{|c|c|c|c|c|}
\hline \multirow[t]{2}{*}{ Grain growth rate } & \multicolumn{2}{|l|}{1988} & \multicolumn{2}{|l|}{1989} \\
\hline & $\begin{array}{l}\text { Well- } \\
\text { watered }\end{array}$ & $\begin{array}{l}\text { Drought- } \\
\text { stressed }\end{array}$ & $\begin{array}{l}\text { Well- } \\
\text { watered }\end{array}$ & $\begin{array}{l}\text { Drought- } \\
\text { stressed }\end{array}$ \\
\hline Lag phase (*Cday) & -0.10 & -0.12 & -0.14 & -0.12 \\
\hline $\begin{array}{l}\text { Linear grain growth phase } \\
\text { ("Cday) }\end{array}$ & 0.14 & 0.12 & -0.13 & 0.12 \\
\hline Grain filling period ( ${ }^{\circ} \mathrm{Cday}$ ) & 0.11 & 0.09 & -0.20 & 0.08 \\
\hline $\begin{array}{l}\text { Grain growth rate } \\
\qquad\left(\mathrm{mg} \mathrm{grain}^{-1}{ }^{\circ} \mathrm{Cday}^{-1}\right)\end{array}$ & -0.03 & 0.02 & 0.06 & -0.04 \\
\hline Final grain mass (mg grain ${ }^{-1}$ ) & 0.09 & 0.18 & -0.05 & 0.24 \\
\hline $\begin{array}{l}\text { Panicle grain yield } \\
\text { (g panicle } \\
-1 \text { ) }\end{array}$ & -0.12 & $0.62^{* * *}$ & 0.26 & $0.78^{* * *}$ \\
\hline Threshing percentage $(\%)$ & -0.12 & $0.48^{* *}$ & -0.03 & $0.44^{* *}$ \\
\hline Time to lowering (days) & -0.07 & 0.12 & 0.08 & 0.07 \\
\hline Grain yield $\left(\mathrm{g} \mathrm{m}^{-2}\right)$ & -0.10 & $0.69^{* *}$ & 0.03 & $0.71^{* *}$ \\
\hline
\end{tabular}

${ }^{* *} P<0.01$

\section{TABLE 5}

Relationship between certain parameters of grain growth and the reduction in grain filling period and grain mass as a result of postflowering drought stress. Postflowering drought screening trials. ISC, dry seasons 1988 and 1989

Year

Reduction in

$\begin{array}{lll}\begin{array}{l}\text { Grain filling } \\ \text { period }\end{array} & \begin{array}{l}\text { Grain filling } \\ \text { rate }\end{array} & \text { Grain mass }\end{array}$

\begin{tabular}{|c|c|c|c|c|}
\hline \multicolumn{5}{|l|}{ Well-watered conditions } \\
\hline Grain filling period & 1988 & $0.62^{* *}$ & -0.17 & $0.44^{* *}$ \\
\hline ( ${ }^{\circ}$ Cday $)$ & 1989 & $0.68^{* * *}$ & $-0.59^{* *}$ & $0.44^{* *}$ \\
\hline Grain growth rate & 1988 & -0.23 & 0.04 & -0.13 \\
\hline $\begin{array}{l}\text { (mg grain } \\
\left.{ }^{a} \mathrm{Cday}^{-1}\right)\end{array}$ & 1989 & $-0.37^{*}$ & $0.56^{* * *}$ & -0.13 \\
\hline Grain mass & 1988 & 0.27 & -0.17 & 0.25 \\
\hline$\left(\right.$ mg grain $\left.^{-1}\right)$ & 1989 & $0.46^{* \pi}$ & -0.14 & $0.47^{* *}$ \\
\hline \multicolumn{5}{|l|}{ Stress conditions } \\
\hline Grain filling period & 1988 & $-0.52^{*}$ & $0.32^{*}$ & $-0.43^{* *}$ \\
\hline ( ${ }^{\circ}$ Cday $)$ & 1989 & $-0.72^{* *}$ & $0.43^{* *}$ & $-0.56^{* *}$ \\
\hline Grain growth rate & 1988 & 0.10 & $-0.65^{* *}$ & -0.14 \\
\hline $\begin{array}{l}\text { (mg grain }{ }^{-1} \\
=\text { Cday }^{-1} \text { ) }\end{array}$ & 1989 & $0.53^{* *}$ & $-0.74^{* * *}$ & 0.06 \\
\hline Grain mass & 1988 & $-0.30^{*}$ & -0.18 & $-0.47^{* *}$ \\
\hline (mg grain ${ }^{-1}$ ) & 1989 & $-0.42^{* *}$ & 0.11 & $-0.72^{* *}$ \\
\hline
\end{tabular}

$m P<0.05 ; * * P<0.01$. 


\section{Grain growth and drought response}

To explore the role of grain growth parameters in drought tolerance, correlation analysis of grain growth parameters of a subset of 34 lines (which flowered from 59 to 71 days after sowing) to DRI was carried out for both years (Table 4 ). None of the grain growth parameters and final grain mass under both well-watered and postflowering drought conditions were related to drought response (i.e. to DRI). The relationship between grain yield in stress and GGR in 1988 (Table 3) thus appears to be an expression of drought escape, a consequence of the positive relationships of both yield under postflowering stress and GGR, with early flowering.

There were meaningful relationships between certain growth parameters and the changes in GFP and grain mass caused by postflowering drought stress (Table 5). Lines with long GFP in well-watered conditions had significantly $(P<0.001)$ larger reductions in GFP and grain mass in the stress. Lines with high GGR under well-watered conditions, however, were not more likely to have larger reductions in grain mass under stress. The extent of the reduction of GFP was associated ( $r=0.79$ in 1988 and $r=0.70$ in 1989) with the reduction in grain mass, as expected.

\section{DISCUSSION}

Pearl millet is known to vary greatly in grain mass (Burton and Powell, 1968; Rachie and Majmudar, 1980), a finding this study corroborates, with genetic material mostly of Sahelian origin. Differences between lines in grain mass were mostly due to differences in length of LGGP, and to a lesser extent to differences in GGR, confirming the finding for a smaller set of lines (Fussell and Pearson, 1980). These differences were evident in the well-watered but less so in the stress conditions. The magnitude of the variations in the various grain growth parameters (more than two-fold in both years and both moisture environments) appears sufficient for effective utilization of grain growth parameters in a pearl millet breeding program, if there were a reason to do so.

The principal effect of postflowering drought stress on grain growth was to reduce grain mass. This occurred primarily through a reduction in GFP rather than GGR for a large majority of the lines tested. Similar findings have been reported for maize (Zea mays L.) (Ouattar et al., 1987a). Truncation of GFP could have resulted from a limited assimilate supply or (and) a reduced grain storage capacity. In maize, restricted current photosynthate production caused by water deficit was implicated as the cause of reduced grain mass under postflowering drought stress (Ouattar et al., 1987b). Water deficit during the LP could have reduced the grain storage capacity, determined by cell division during that phase of grain development, as found in maize (Ouattar et al., 
1987a). Because the length of LP was little affected by the drought stress imposed, a restricted current assimilate supply appears a more likely explanation for the reduced grain mass and early cessation of grain filling than a decreased storage capacity.

The maintenance of GGR under drought stress implies that pearl millet possesses robust adaptation mechanisms to ensure seed production. Two sources of assimilate supply are available to maintain grain filling: firstly, current photosynthate from photosynthetic activity after anthesis and, secondly, translocation of stored carbohydrates produced before anthesis. Severe water stress is known to cause stomatal closure in pearl millet (Black and Squire, 1979; Squire, 1979; Henson et al., 1981) and, presumably, a reduction in photosynthate production. However, a lack of current assimilation can be buffered by mobilization of sugars stored in the stems in many cereal crops. Fussell et al. (1980) and Pande et al. (1983) observed that soluble sugars stored in stems prior to grain filling in pearl millet were mobilized during grain filling. In maize, under water-deficit conditions, the assimilates stored before anthesis were estimated to contribute $26-30 \%$ of final grain weight (Jurgens et al., 1978; Ouattar et al., 1987b). Quantification of the contribution of stored stem sugars to final grain mass under either well-watered or droughted conditions has yet to be done for pearl millet.

Consistent relationships between grain yield under drought stress and grain growth parameters were found only for GFP and grain mass. There are similar reports for wheat (Sayed and Gadallah, 1983; Bruckner and Frohberg, 1987). Furthermore, there were no consistent associations between grain growth parameters and DRI, suggesting that none of the grain growth parameters measured were expressions of drought tolerance or susceptibility. Therefore, selecting for grain growth parameters to enhance postflowering drought tolerance in pearl millet appears not to be feasible.

However, exploiting certain drought-escape features observed for the grain growth parameters does appear a possible appraoch to improving yield under postflowering drought stress. Lines with shorter GFP under well-watered conditions had smaller reductions in both GFP and grain mass under stress. Moreover, lines with higher GGR in well-watered conditions had smaller reductions in GFP. Therefore, a viable risk-reducing strategy for areas prone to postflowering stress would be to select lines with high GGR combined with relatively short GFP. Bruckner and Frohberg (1987) proposed a similar pattern under postflowering drought stress in wheat. Selecting for high GGR and shorter GFP by direct measurement in a large number of pearl millet lines may require too many observations and not be cost effective.

\section{ACKNOWLEDGEMENTS}

P. Bieler thanks the Swiss Directorate for Development Cooperation and Humantarian Aid for financial support while doing part of this research. The 
help of Jimmy Adeyemi, Boubacar Mara, Monkeila Boriema, Moustapha Amadou, Ene Nweze, and the Farm Operations Program of the ICRISAT Sahelian Center is gratefully acknowledged.

\section{REFERENCES}

Bishnoi, O.P., Umamaheshwara Rao, V. and Singh, D., 1985. Heat unit requirement for growth and development of pearl millet. Ann. Arid Zone, 24: 241-250.

Black, C.R. and Squire, G.R., 1979. Effects of atmospheric saturation deficit on the stomatal conductance of pearl millet (Pentisetum typhoides S. and H.) and groundnut (Arachis hlpogaca L. ). J. Exp. Bol., 30: 935-945.

Bruckner, P.L. and Frohberg, R.C., 1987. Rate and duration of grain fill in spring wheat. Crop Sci., 27: 451-455.

Burton, G.W. and Powell, J.B., 1968. Pearl millet breeding and cytogenetics. Adv, Agron., 12: $187-188$.

Forest, F., 1982. Evolution de la pluviométric en zone soudano-sahélienne au cours de la période 1940-79 et conséquences sur le bilan hydrique des cultures pluviales au Sénégal. Agron. Trop. (Paris), 37: 17-23.

Fussell, L.K. and Pearson, C.J., 1978. Course of grain development and its relationship to black region appearance in Pennisetum anericanmm. Field Crops Res., 1: 21-31.

Fussell, L.K., Pearson, C.J. and Norman, M.J.T., 1980. Effect of temperature during various growth stages on grain development and yield of Pennisetum americamum. J. Exp. Bol., 31: $621-633$.

Fussell, L.K., Bidinger, F.R. and Bieler, P., 1991. Crop physiology and breeding for drought tolerance: research and development. Field Crops Res., 27: 183-199.

Garcia-Huidobro, J., Monteith, J.L. and Squire, G.R., 1982. Time, temperature and germination of pearl millet (Pennisetum typhiodes S. \& G.). I. Constant temperature. J. Exp. Bot., 33: $288-296$.

Henson, I.E., Mahalakshmi, V., Bidinger, F.R. and Alagarswamy, G., 1981. Stomatal responses of peal millet (Pennisetum americanum (L.) Lecke), in relation to abscisic acid and water stress. J. Exp. Bol., 32: 1211-1221.

Johnson, D.R. and Tanner, J.W., 1972. Calculation of the rate and duration of grain filling in corn (Zea mays L.). Crop Sci., 12: 485-486.

Jones, D.B., Peterson, M.L. and Geng, S., 1979. Association between grain filling and yield components in rice. Crop Sci., 19:641-643.

Jurgens, S.K., Johnson, R.R. and Boyer, J.S., 1978. Dry matter production and translocation in maize subjected to drought during grain fill. Agron. J., 70: 678-682.

Mahalakshmi, V. and Bidinger, F.R., 1985. Water stress and time of floral initiation in pearl millet. J. Agric. Sci. (Camb.), 105: 437-445.

Maiti, R.K. and Bidinger, F.R., ${ }^{1981}$. Growth and development of the pearl millet plant. ICRISAT Res. Bull. No. 6.

Ong, C.K., 1983. Response to temperature in a stand of pearl millet (Pennisetum typhoides, S. \& H.). II. Reproductive development. J. Exp. Bot., 34: 337-348.

Ong, C.K. and Monteith, J.L., 1985. Response of pearl millet to light and temperature. Field Crops Res., 11:141-160.

Ouattar, S., Jones, R.J. and Crookston, R.K., 1987a. Effect of water deficit during grain filling on the pattern of maize kernel growth and development. Crop Sci., 27: 726-730.

Ouattar, S., Jones, R.J., Crookston, R.K. and Kajeiou, M., 1987b. Effect of drought on water relations of developing maize kernels. Crop Sci., 27: 730-735. 
Pande, P.C., Pokhriyal, S.C. and Balzor Singh. 1983. Heterosis in grain sink activity in pearl millet. Indian J. Genet., 43: 409-413.

Rachie. K.O. and Majmudar. J.V., 1980. Pearl millet. Pennsylvania State University Press, University Park, PA, 307 pp.

Sayed. H.I. and Gadallah, A.M., 1983. Variation in dry matter and grain filling characteristics in wheal cultivar's. Field Crops Res., 7; 61-71.

Sivakumar, M.V.K., 1986. Soil climatic zonation for West African semi-arid tropics - implications of millet improvement. Paper presented at the Regional Millet Workshop, September 1986. Niamey, Niger. ICRISAT Sahelian Centre [limited distribution].

Sivakumar, M.V.K., 1987. Agroclimatic aspects of rainfed agriculture in the Sudano-Sahelian zone. Paper presented at the Workshop on Soil, Water and Crop/Livestock Managemen1 Systems for Rainfed Agriculture in the Sudano-Sahelian Zone, I 1-17 January 1987, Niamey, Niger, $3 ! \mathrm{pp}$.

Sivakumar, M.V.K., 1989. Climatic changes and crop production patterns in the Sudano-Sahelian zone. A paper presented at the OAU/STRC SAFGRAD/PAN-EARTH/ISRA Workshop on the Effects of Climatic Changes on the Agricultural and Ecological Systems in SubSaharan Africa; 11-15 September 1989, Saly, Senegal. ICRISAT Sahelian Centre [limited distribution ].

Squire, G.R., 1979. The response of stomata of pearl millet (Pennisetum typhoides S. and H.) to atmospheric humidity. J. Exp. Bot., 30: 925-933. 